\title{
Optimized expansion of the Wallstent compared with the Palmaz-Schatz stent: On-line observations with two- and three-dimensional intracoronary ultrasound after angiographic guidance
}

\author{
Clemens von Birgelen, MD, Robert Gil, MD, Peter Ruygrok, MD, Francesco Prati, MD, \\ Carlo Di Mario, MD, PhD, Wim J. van der Giessen, MD, PhD, Pim J. de Feyter, MD, PhD, and \\ Patrick W. Serruys, MD, PhD Rotterdam, The Netherlands
}

\begin{abstract}
Optimized stent expansion by high-pressure inflations of oversized balloons has initially been derived from experience obtained with the Palmaz-Schatz stent, whereas there is little experience with this strategy in the Wallstent. By using this approach with quantitative coronary angiographic guidance, 20 Wallstents and 20 Palmaz-Schatz stents were implanted in 34 patients and consecutively examined by conventional two-dimensional (2D) intracoronary ultrasound (ICUS) and three-dimensional (3D) ICUS on the basis of the application of a pattern recognition algorithm. Ultrasound criteria of adequate stent expansion were defined as a complete apposition of the stent to the vessel wall, a stent symmetry index ( $\mathrm{SSI}=$ minimum/maximum lumen diameter) $\geq 0.7$, and a stent-reference lumen area ratio (SRR = Minimum intrastent lumen area/Average of proximal and distal reference lumen area) $\geq 0.8$. In all cases a smooth angiographic lumen and a negative diameter stenosis, on the basis of a distal reference, was achieved. For the Wallstents ICUS showed a higher SSI (2D, $0.95 \pm 0.04$ vs $0.85 \pm 0.09$; $p<0.001 ; 3 \mathrm{D}, 0.90 \pm 0.09$ vs $0.82 \pm 0.11, p<0.05)$ and $a$ lower SRR (2D, $0.66 \pm 0.12$ vs $0.81 \pm 0.13, p<0.005 ; 3 D$, $0.63 \pm 0.14$ vs $0.74 \pm 0.15, p<0.05$ ) than for the PalmazSchatz stents. Ninety percent of failure in meeting these criteria resulted from a low SRR. The incidence of incomplete stent apposition (one in both stents) or SSI $<0.7$ was low and generally associated with an SRR $<0.8$. The Wallstents met the ICUS criteria less often (2D, $2(10 \%)$ vs $10(50 \%), p<0.01$; $3 \mathrm{D}, 3(15 \%)$ vs $9(45 \%), p<0.05)$, were significantly longer $(35.1 \pm 7.7 \mathrm{~mm}$ and $14.3 \pm 3.3 \mathrm{~mm}, p<0.0001)$, and generally demonstrated a larger vessel tapering, measured as proximal minus distal ICUS reference lumen area $(1.33 \pm 2.91$ $\mathrm{mm}^{2}$ vs $0.44 \pm 1.97 \mathrm{~mm}^{2}$, not significant). Wallstents meet-
\end{abstract}

From the Thoraxcenter, Division of Cardiology, University Hospital, Erasmus University.

Dr, von Birgelen is a recipient of a fellowship of the German Research Society (DFG, Bonn, Germany).

Received for publication Sept. 12, 1995; accepted Oct. 23, 1995.

Reprint requests: Patrick W. Serruys, MD, PhD, Thoraxcenter, Erasmus University Rotterdam, Cardiac Catheterization and Intracoronary Imaging Laboratory, P.O. Box 1738, 3000 DR Rotterdam, The Netherlands.

Copyright (C) 1996 by Mosby-Year Book, Inc.

$0002-8703 / 96 / \$ 5.00+0 \quad \mathbf{4} / \mathbf{1} / \mathbf{7 1 3 6 0}$ ing the ICUS criteria, however, showed less vessel tapering $\left(0.18 \pm 1.64 \mathrm{~mm}^{2}\right)$. Thus optimized stent expansion was followed by excellent angiographic results for both PalmazSchatz and Wallstent. Although angiographic results and visual assessment of the ICUS examination suggested a good outcome, few Wallstents met the ICUS criteria in contrast to the Palmaz-Schatz stents. The low value of the SRR in the Wallstents is likely to be caused by vessel tapering, suggesting that this criterion may be unsuitable in assessing the adequacy of the expansion of relatively long stents such as the Wallstent. (Am Heart J 1996;131:1067-75.)

Until recently coronary stenting has in many centers been performed only for acute or threatening vessel occlusion after balloon angioplasty. ${ }^{1-8}$ The initial enthusiasm for coronary stenting ${ }^{9}$ had been tempered by the high incidence of subacute thrombosis, which now appears to be significantly reduced by many factors, including coating the stent with heparin. ${ }^{10}$ Optimization of the results of stenting, first promoted by the Milano group, ${ }^{11-13}$ which performed high-pressure inflations of oversized balloons inside stents with intracoronary ultrasound (ICUS) guidance, is an alternative approach to meet the challenge of subacute stent thrombosis. Initial experience suggests ${ }^{11}$ that this approach may even reduce the incidence of restenosis after coronary stenting. ${ }^{14,15}$ By changing the technique of coronary stenting from a more restrained to this vigorous approach, the problem of subacute occlusion ${ }^{16}$ could be minimized, permitting stenting without anticoagulation and the inherent risk of bleeding. ${ }^{11}$ The reduced incidence of subacute thrombosis by optimized stent deployment is achieved at the expense of a small but not insignificant risk of coronary dissection and rupture, ${ }^{12,17}$ emphasizing the necessity of defining certain criteria for safe and effective guidance of the intervention. 
Table I. Characteristics of the population and stenting procedures

\begin{tabular}{lcc}
\hline & Wallstent & $\begin{array}{c}\text { Palmaz-Schatz } \\
\text { stent }\end{array}$ \\
\hline Stents & 20 & 20 \\
Patients & 18 & 16 \\
Patients with multiple & $2(15 \%)$ & $4(25 \%)$ \\
$\quad$ stents & & \\
Age (yrs) & $60.5 \pm 8.8$ & $60.9 \pm 8.4$ \\
Male sex & $13(72 \%)$ & $11(69 \%)$ \\
Vessels & $3(15 \%)$ & $9(45 \%)$ \\
$\quad$ LAD & 0 & $1(5 \%)$ \\
$\quad$ LCX & $9(45 \%)$ & $10(50 \%)$ \\
RCA & $8(40 \%)$ & 0 \\
$\quad$ SVG & $35.1 \pm 7.7$ & $14.3 \pm 3.3 p<0.00001$ \\
Nominal stent length & &. \\
$\quad$ (mm) & $4.2 \pm 0.6$ & $3.6 \pm 0.4 p<0.005$ \\
Largest balloon (mm) & $15.1 \pm 2.6 \mathrm{NS}$ \\
Maximum pressure* & $14.7 \pm 3.7$ & \\
$\quad$ (atm) & & $1.3 \pm 0.2 \mathrm{NS}$ \\
Balloon:artery ratio & $1.4 \pm 0.3$ & \\
\hline
\end{tabular}

$L A D$, Left anterior descending coronary artery; $L C X$, left circumflex coronary artery; $R C A$, right coronary artery; $S V G$, saphenous vein graft.

*Maximum pressure in the largest balloon.

Because the new concept has initially been applied with Palmaz-Schatz stents (Johnson \& Johnson, Warren, N.J.), the ICUS criteria for optimized stent deployment ${ }^{11-13}$ were primarily made on the basis of this stent with little experience in high-pressure expansion of the Wallstent (Schneider, Bulach, Switzerland), which has a characteristic structural design, length, and clinical application ${ }^{18-22}$ that differs considerably from the Palmaz-Schatz stent. ${ }^{23,24}$ This observational study compares the practice and results of the optimized deployment of 20 Wallstents and 20 Palmaz-Schatz stents with quantitative angiography for guiding the procedure and ICUS for assessing the result. Because the potential of two- (2D) and three-dimensional (3D) ICUS in assessing the vessel wall ${ }^{25-29}$ and stent ${ }^{30,31}$ geometry and the adequacy of stent deployment ${ }^{11-13,32-36}$ has recently been demonstrated, both conventional $2 \mathrm{D}$ and on-line reconstructed 3D ICUS were applied.

\section{METHODS}

Study population. The results of implantation of 20 Wallstents and 20 Palmatz-Schatz stents in American College of Cardiology/American Heart Association type B or $\mathrm{C}$ lesions ${ }^{37,38}$ without angiographic evidence of major calcification were examined on-line by quantitative coronary angiography and ICUS. The Wallstents were implanted in 18 patients and the Palmaz-Schatz stents in 16 patients aged $60.7 \pm 8.5$ years (range 46 to 73 years). The Wallstents were significantly longer than the PalmazSchatz stents $(p<0.0001)$. Table I gives further details.
Interventional procedure. All patients received $250 \mathrm{mg}$ aspirin and 10,000 $U$ heparin intravenously. During the entire procedure the activated clotting time was measured hourly and intravenous heparin was administered if required to maintain an activated clotting time of $>300 \mathrm{sec}-$ onds. After intracoronary injection of isosorbide dinitrate, the initial on-line quantitative coronary angiography (QCA) was performed. Predilation of the lesion by conventional balloon angioplasty was performed. The interpolated angiographic reference lumen diameter provided by QCA, the lesion length, and the presence of adjacent side branches were taken into account to select an appropriately sized self-expandable Wallstent. The nominal Wallstent diameter chosen was generally $1.5 \mathrm{~mm}$ larger than the interpolated reference diameter. A delivery balloon with a diameter corresponding to the interpolated reference lumen diameter was used to implant the PalmazSchatz stents.

Additional balloon inflations were performed inside all stents with a low-compliance balloon catheter with at least an $0.25 \mathrm{~mm}$ larger diameter than the interpolated angiographic lumen reference and a pressure of at least $14 \mathrm{~atm}$. Progression to larger balloons was permitted to achieve a satisfactory angiographic result. Thus balloons with a maximum size of $4.2 \pm 0.6 \mathrm{~mm}$ for the Wallstent and $3.6 \pm 0.4 \mathrm{~mm}$ for the Palmaz-Schatz stent $(p<0.005)$ were inflated with maximum pressures of $14.7 \pm 3.7 \mathrm{~atm}$ and $15.1 \pm 2.6 \mathrm{~atm}$ (not significant, NS), respectively (Table I). The balloon/artery ratio was $1.4 \pm 0.3$ and $1.3 \pm 0.2$, respectively (NS). In the relatively long Wallstents the largest balloon size and the maximum pressure were frequently applied to only the proximal part of the stented segment. An angiographic appearance of a smooth lumen of the stented segment and a negative distal referencebased diameter stenosis were considered to be the procedural end points on the basis of QCA. After administration of intracoronary nitrates, the stented segment was examined by ICUS.

Quantitative coronary angiography. The computerbased Coronary Angiography Analysis System (CAAS II, Pie Medical Data, Maastricht, The Netherlands), previously described and validated in detail $,^{39}, 40$ was used to perform a geometric quantitative analysis. The boundaries of a selected coronary segment were detected by using a weighted sum of the first and second derivative functions of the brightness profile of each vessel scan. The absolute angiographic diameter of the stenosis was determined by using a contrast-free guiding catheter as a scaling device. ${ }^{39}$ The measurements we performed on-line after intracoronary nitrates in two orthogonal views. Before stenting, the diameter function was used to determine the minimal lumen diameter, a computer-derived estimation of an interpolated reference diameter at the site of the lesion, and the obstruction length (Fig. 1). The interpolated diameter stenosis before stenting was calculated as (Intrastent minimal lumen diameter/Interpolated reference diameter) $\times 100 \%$.

Because the segments directly adjacent to the stent are involved in the process of luminal enlargement after opti- 


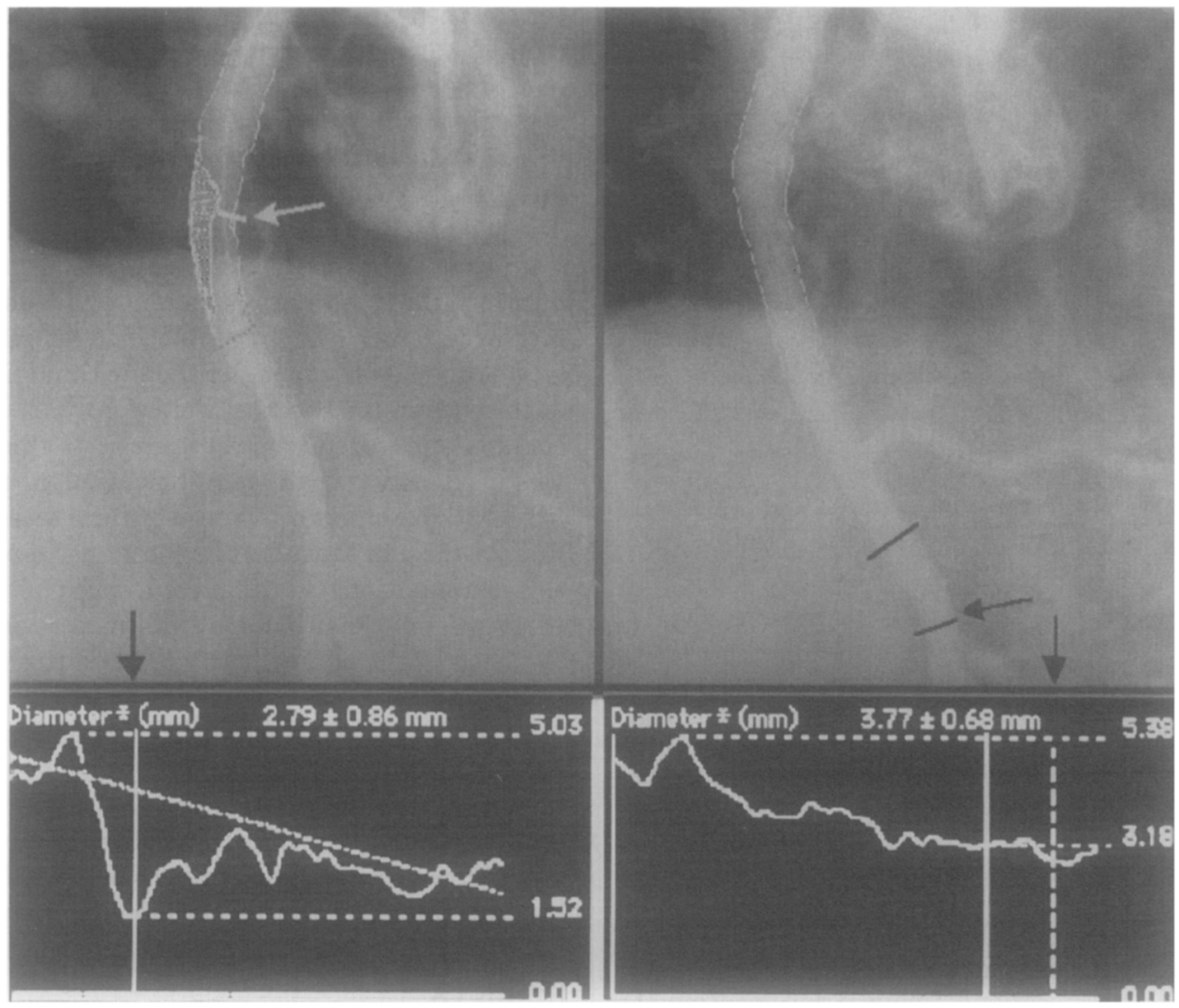

Fig. 1. Quantitative coronary angiography before (left) and after implantation of Wallstent (right) by CAAS II analysis system. On angiograms site of minimum lumen diameter is indicated by line. Arrowhead indicates site of reference measurement. Before stenting (left) interpolated reference at site of minimal lumen diameter was used to measure interpolated diameter stenosis. To calculate diameter stenosis after stenting (right) angiographically undiseased site up to $1 \mathrm{~cm}$ distal to stent was used as reference, showing diameter similar to interpolated reference before stenting.

mized stenting, the interpolated reference diameter was not used to calculate the percent diameter stenosis after stenting but the lumen diameter of an angiographically undiseased reference up to $1 \mathrm{~cm}$ distal to the stent without major side branches between the stent and the reference site (Fig. 1). The minimal lumen diameter was measured in the stented segment of the artery and the distal reference-based diameter stenosis after stenting was calculated as (Intrastent minimum lumen diameter/Distal reference lumen diameter) $\times 100 \%$.

Image acquisition of ICUS. A $30-\mathrm{MHz}$ single-element long-monorail ultrasound catheter with a $2.9 \mathrm{~F}$ echotransparent distal sheath was used (MicroView, CVIS, Sunnyvale, Calif.). The common lumen of the sheath accomodates the imaging core and the guide wire but never both simultaneously. ICUS imaging was performed during a motorized uniform speed $(1 \mathrm{~mm} / \mathrm{sec}$ ) pullback of the transducer inside the stationary imaging sheath, which allowed the transducer to move at the same speed as the ICUS handgrip inside the pullback device. The video signal was recorded on a high-resolution super VHS tape for conventional ICUS analysis.

Assessment by ICUS. After the pullback of the ultra- sound catheter was completed, the videotape was used to obtain lumen area measurements of the ICUS references that were by definition 3 to $5 \mathrm{~mm}$ proximal and distal to the stented segment. Stent apposition to the vessel wall was reviewed over the entire stented segment. The ICUS image with the minimal intrastent lumen area was found by scrolling the videotape back and forth. On this crosssection, the lumen area was manually traced and the stent symmetry was assessed by measuring the minimum and maximum lumen diameter.

3D reconstruction of ICUS. Simultaneously with the video recording on $s$-VHS tape, video signals were also transferred to a 3D ICUS system (EchoQuant, Indec Systems Inc., Capitola, Calif.) that automatically acquires 8.5 images per second so that contiguous tomographic ICUS image slices, $118 \mu \mathrm{m}$ apart, could be reconstructed on-line. The memory capacity of the 3D system operated by a second analyst allowed the acquisition and processing of a maximum of 255 images within 2 minutes; thus segments up to $30 \mathrm{~mm}$ long could be reconstructed. If Wallstents were longer than $30 \mathrm{~mm}$, ICUS images recorded on videotape were used to reconstruct the proximal part of these stents. 


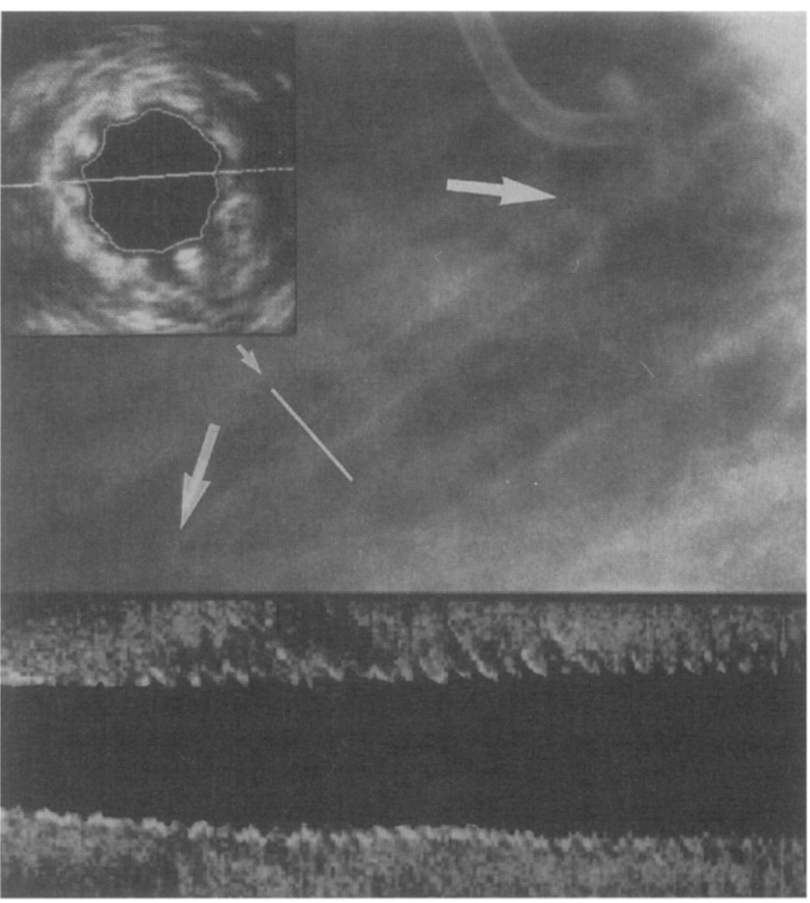

Fig. 2. Wallstent after implantation in left anterior descending coronary artery. Arrowheads indicate proximal and distal ends of stent on radiographic image (upper panel). Location of 2D ICUS image (insert) is indicated by small arrowhead. Cross-sectional image is derived from 3D analysis system, performing semiautomated detection of blood pool on basis of application of pattern recognition algorithm. Longitudinal view (lower panel) is reconstructed, showing smooth tapering of luminal dimensions from proximal (right) to distal (left). Besides 3D, conventional $2 \mathrm{D}$ analysis was performed in this study on basis of review of videotape and manual contour tracing.

Assessment by 3D ICUS. The 3D system provided a longitudinally reconstructed view (Fig. 2) that could be rotated around the longitudinal axis of the vessel segment. Furthermore, a cylindrical format was displayed cut open lengthwise and tilted back. The cylindrical view and more frequently the longitudinal display were used to evaluate the adequacy of stent strut apposition to the vessel wall. Automated image segmentation, on the basis of a pattern recognition algorithm (Acoustic Quantification ${ }^{25}$ that has previously been validated, ${ }^{41}$ provided on the cross-sectional ICUS images of the entire reconstructed segment the measurement of the lumen area and the minimum and maximum diameters. The detected contour, indicating the lumen-intima boundary, was rapidly checked and manual correction could be performed on individual ICUS crosssections. A display of the lumen area and corresponding diameter measurements facilitated the assessment. The minimum lumen area and the minimum and maximum lumen diameters were measured.

Adequate stent expansion by ICUS. During the ultrasound examination of the entire segment, criteria on the basis of our previous experience and slightly modified cri- teria of the Italian group ${ }^{11}$ were applied to define adequate stent deployment. First, good apposition to the vessel wall had to be found at all sites of the stented segment. Moreover, the stent symmetry index (SSI), defined as ratio of minimal divided by maximal intrastent diameter, had to $b e \geq 0.7$ at the site of the minimal intrastent lumen area. The adequacy of the intrastent lumen area finally achieved was assessed by the stent-reference lumen area ratio (SRR), a ratio of the minimum intrastent divided by reference lumen area, which had to be $\geq 0.8$. The reference lumen area was defined as the mean of the proximal and distal reference measurements; however, if only a single reference could be measured (e.g., ostial lesion), this measurement was used alone to calculate the SRR. During both $2 \mathrm{D}$ and 3D ICUS examinations, these criteria were applied to define an adequate result after the stenting procedure. After this examination was completed, each operator was free to perform additional balloon inflations inside the stent on the basis of the clinical situation and the angiographic or ICUS findings.

Statistics. Measurements of continuous parameters are given as mean $\pm 1 \mathrm{SD}$. The two-tailed student's $t$ test for unpaired data analysis was used to compare the Wallstent group with the Palmaz-Schatz stent group, and a $p$ value of $<0.05$ was considered statistically significant. Categorical variables were assessed using chi-square statistics.

\section{RESULTS}

Initial QCA. In the Wallstent and Palmaz-Schatz stent groups the minimal lumen diameter was $1.26 \pm 0.48 \mathrm{~mm}$ and $1.04 \pm 0.23 \mathrm{~mm}$ (NS) before stenting, and the obstruction length was $12.24 \pm 4.25$ $\mathrm{mm}$ and $8.18 \pm 3.21 \mathrm{~mm}(p<0.005)$, respectively. The interpolated reference diameter was $3.04 \pm 0.76$ $\mathrm{mm}$ and $2.86 \pm 0.55 \mathrm{~mm}(\mathrm{NS})$, and the interpolated diameter stenosis was $58.1 \% \pm 12.6 \%$ and $60.9 \% \pm$ $9.2 \%$ (NS), respectively.

Angiographic results and clinical outcome. After stenting, a smooth lumen of the stented segment was obtained in all angiographic views and the QCA analysis revealed a negative distal reference-based diameter stenosis in all Wallstents and PalmazSchatz stents. The QCA results after the Wallstent and Palmaz-Schatz stent implantation did not differ significantly. In both the Wallstent and PalmazSchatz stent groups, a significant increase in the minimal lumen diameter and reduction of the percent diameter stenosis (Fig. 3) was observed ( $p<$ 0.0001 for both). The minimal lumen diameter after stenting was $2.95 \pm 0.39 \mathrm{~mm}$ for the Wallstent and $3.19 \pm 0.51 \mathrm{~mm}$ for the Palmaz-Schatz stent (NS), and the distal reference-based diameter stenosis was $-18.0 \% \pm 11.2 \%$ and $-17.3 \% \pm 10.0 \%(\mathrm{NS})$, respectively. The interpolated reference diameter obtained before stenting and the distal reference diameter after stenting $(2.84 \pm 0.39 \mathrm{~mm}$ and $2.95 \pm 0.45 \mathrm{~mm}$ 


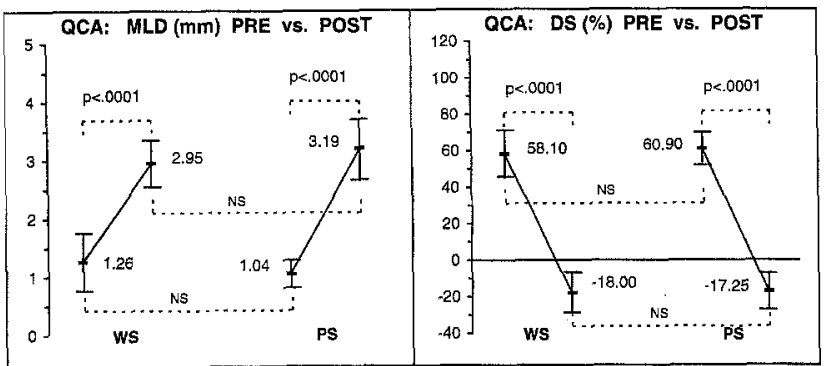

Fig. 3. QCA measurements before(PRE) and after(POST) implantation of Wallstent (WS) or Palmaz-Schatz stent (PS). In both stent groups minimal lumen diameter (MLD) increased significantly after stenting (left panel). Diameter stenosis (DS), derived from interpolated reference before and distal reference measurement after stenting, was significantly reduced by intervention. Between Wallstents and Palmatz-Schatz stents no significant difference was observed.

(NS) for the Wallstent group and Palmaz-Schatz stent group, respectively) did not differ significantly.

On the basis of QCA criteria of a smooth stented segment lumen and the realization of a negative percent diameter stenosis, all Wallstents and Palmaz-Schatz stents were successfully implanted. Anticoagulation was performed with aspirin and coumadine or ticlopidine at the operator's discretion. No procedural or post-procedural complications were encountered in either group before discharge.

ICUS assessment after stenting. The stent symmetry index (SSI) was significantly higher in the Wallstent than Palmaz-Schatz stent group (Table II). This difference was even more pronounced in the 2D $(p<0.001)$ than the 3D ICUS results $(p<0.05)$, demonstrating an SSI of $0.95 \pm 0.04$ and $0.90 \pm 0.09$ for the Wallstent group and $0.85 \pm 0.09$ and $0.82 \pm 0.11$ for the Palmaz-Schatz stent group, respectively. A significantly lower value of the stentreference lumen area ratio (SRR) was measured in the Wallstent group compared with the PalmazSchatz stent group with both $2 \mathrm{D}(0.66 \pm 0.12$ vs $0.81 \pm 0.13, p<0.005)$ and 3D ICUS $(0.63 \pm 0.14 \mathrm{vs}$ $0.74 \pm 0.15, p<0.05)$. The minimal lumen area of the Wallstents was slightly lower (NS) than the minimal lumen area of the Palmaz-Schatz stents $\left(7.65 \pm 2.05 \mathrm{~mm}^{2}\right.$ vs $8.98 \pm 2.78 \mathrm{~mm}^{2}$ by 2 D ICUS and $7.62 \pm 2.01 \mathrm{~mm}^{2}$ vs $8.49 \pm 3.18 \mathrm{~mm}^{2}$ by $3 \mathrm{D}$ ICUS). No significant difference between the results of 2D and 3D ICUS measurements for the different parameters was found (Table II).

Two (10\%) Wallstents and 10 (50\%) Palmaz-Schatz stents $(p<0.01)$ met the ICUS criteria of adequate stenting by 2D ICUS (Fig. 4). By using 3D ICUS, 3 (15\%) Wallstents and $9(45 \%)$ Palmaz-Schatz stents

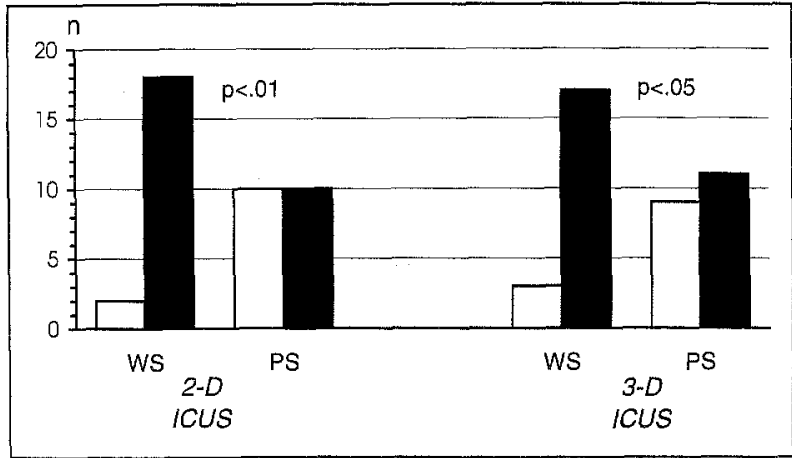

Fig. 4. ICUS criteria of adequate stent expansion met (white bars) or not met (black bars). Both conventional 2D and 3D analysis of ICUS images demonstrated that Wallstents (WS) met ICUS criteria less frequently than the Palmaz-Schatz stents (PS).

were found to meet the ICUS criteria of adequate stent expansion $(p<0.05)$. A low SRR was the main reason for $>90 \%$ of the failures in meeting the criteria. The incidence of an incomplete stent apposition to the vessel wall or an SSI $<0.7$ was low and mostly associated with a low SRR (Table III). The average ICUS reference lumen area was $12.50 \pm 3.41 \mathrm{~mm}^{2}$ proximally and $11.17 \pm 3.07 \mathrm{~mm}^{2}$ distally for the Wallstent group and $11.34 \pm 2.68 \mathrm{~mm}^{2}$ proximally and $10.89 \pm 3.13 \mathrm{~mm}^{2}$ distally for the Palmaz-Schatz stent group. Consequently, the tapering of the lumen area along the entire stented segment was higher (NS) in the Wallstent group $\left(1.33 \pm 2.91 \mathrm{~mm}^{2}\right)$ compared with the Palmaz-Schatz stent group $\left(0.44 \pm 1.97 \mathrm{~mm}^{2}\right)$. The Wallstents, which met the ultrasound criteria by $2 \mathrm{D}$ or 3D ICUS, had an average tapering of the lumen area of $0.18 \pm 1.64 \mathrm{~mm}^{2}$, and all but one were implanted in bypass grafts.

\section{DISCUSSION}

Procedure and angiographic assessment. On the initial angiogram the minimal stenosis lumen diameter, the reference lumen diameter, and the balloonartery ratio were slightly higher for the Wallstent group, whereas the diameter of the maximum size balloon was significantly higher for these cases when compared with the Palmaz-Schatz stent group. This finding may reflect the fact that $40 \%$ of Wallstents were implanted in saphenous vein grafts, which usually show larger luminal dimensions than native coronary arteries. Indeed, the relatively long Wallstent is frequently implanted in vein grafts $^{18,19}$ or mid-right coronary arteries without concern for side branches.

Recently, the effect of "conventional" nonopti- 
Table II. 2D and 3D ICUS parameters after stenting

\begin{tabular}{llll}
\hline & Wallstent & $\begin{array}{c}\text { Palmaz-Schatz } \\
\text { stent }\end{array}$ & $p$ \\
\hline 2D SSI & $0.95 \pm 0.04$ & $0.85 \pm 0.09$ & $<0.001$ \\
3D SSI & $0.90 \pm 0.09$ & $0.82 \pm 0.11^{*}$ & $<0.05$ \\
2D MLA $\left(\mathrm{mm}^{2}\right)$ & $7.65 \pm 2.05$ & $8.98 \pm 2.78$ & $\mathrm{NS}$ \\
3D MLA $\left(\mathrm{mm}^{2}\right)$ & $7.62 \pm 2.01$ & $8.49 \pm 3.18^{*}$ & NS \\
2D SRR & $0.66 \pm 0.12$ & $0.81 \pm 0.13$ & $<0.005$ \\
3D SRR & $0.63 \pm 0.14$ & $0.74 \pm 0.15^{*}$ & $<0.05$ \\
\hline
\end{tabular}

$M L A$, Minimum lumen area.

*No significant difference between measurements by $2 \mathrm{D}$ and $3 \mathrm{D}$ intracoronary ultrasound.

mized deployment of self-expandable and balloonexpandable stents on the stenosis geometry have been examined by our group on the basis of QCA, which demonstrated a similar improvement in stenosis geometry despite major differences in design and mechanical characteristics of the two stent types. ${ }^{42}$ Also after angiographic optimization of the PalmazSchatz and Wallstent expansion in this study, the residual minimal lumen diameter did not show a statistically significant difference, although the minimal lumen diameter was slightly higher in the Palmaz-Schatz stent group. Nevertheless a smooth lumen contour with a negative distal referencebased diameter stenosis was observed in all stents. Thus no difference between the Palmaz-Schatz and Wallstents was observed in accomplishing an angiographic success.

ICUS assessment. For almost 2 decades angiography has been the standard method of examining the adequacy of coronary interventions..$^{39}$ However, it displays only the opacified luminal silhouette of the vessel. ICUS imaging visualizes the lumen and vessel wall ${ }^{43-45}$ and depicts the stent architecture, permitting careful examination of its dimensions and apposition to the vessel wall. ${ }^{11-13,32-35,46-48}$ The comprehensive insight into vessel and stent geometry provided by ICUS has played an important educational role in triggering and developing the concept of optimized stent deployment. ${ }^{11-13}$ In this study the minimal lumen area of the Wallstent group and $\mathrm{Pal}-$ maz-Schatz stent group did not differ significantly after stent implantation; however, a tendency towards a smaller minimal luminal dimension was found for the Wallstent group in accord with the angiographic findings.

Adequacy of stent expansion by ICUS. The ICUS criteria for safe and effective guidance to optimize stent expansion were developed on the basis of experience with Palmaz-Schatz stents, ${ }^{11-13}$ although there has been little experience with the Wallstent with its characteristic design, length, and application. ${ }^{18-22}$ In
Table III. Adequacy of stent expansion by ICUS

\begin{tabular}{lcc}
\hline & \multicolumn{2}{c}{ Palmaz-Schatz } \\
& Wallstent & stent \\
\hline 2D ICUS & & \\
ICUS criteria fulfilled & $2(10 \%)$ & $10(50 \%)$ \\
ICUS criteria not fulfilled & $18(90 \%)$ & $10(50 \%)$ \\
SRR $<80 \%$ & 18 & 9 \\
SSI $<0.7$ or incomplete apposition & 0 & 1 \\
SRR $<80 \%$ and SSI <0.7 & 0 & 0 \\
3D ICUS & & \\
ICUS criteria fulfilled & $3(\mathbf{1 5} \%)$ & $9(45 \%)$ \\
ICUS criteria not fulfilled & $17(85 \%)$ & $11(55 \%)$ \\
SRR $<80 \%$ & 16 & 9 \\
SSI $<0.7$ or incomplete apposition & 0 & 0 \\
SRR $<80 \%$ and SSI <0.7 & 1 & 2 \\
\hline
\end{tabular}

this study ICUS criteria employed in our center, derived from the experience with Palmaz-Schatz stents, were applied to both Palmaz-Schatz stents and Wallstents to help assess the criteria's value in evaluating optimized Wallstent expansion and to compare the application in the two different types of stents.

No difference in stent apposition to the vessel wall was observed between Palmaz-Schatz stents and Wallstents, but the SSI of both groups differed significantly and demonstrated a more symmetrical lumen shape in the Wallstent. Differences in stent design and mechanical properties between the tubular-slotted Palmaz-Schatz stent and the self-expandable wire-mesh Wallstent, which continues to exert active radial force on the vessel wall after deployment, may explain this finding.

A result that fulfilled the criteria for optimized stenting was achieved in $10 \%$ to $15 \%$ of the Wallstents compared with $45 \%$ to $50 \%$ of the PalmazSchatz stents. Incomplete stent apposition or an SSI $<0.7$ were infrequently observed and not significantly different between the Palmaz-Schatz and Wallstent groups. However, an SRR $<0.8$ despite an optimal angiographic result was responsible for the frequent ICUS-based judgment of inadequate stent deployment and accounted for the differences in fulfillment of the criteria of adequate stent expansion between Palmaz-Schatz stents and Wallstents.

The extent of vessel tapering ${ }^{49}$ along the stented segment appears to be crucial for the SRR and may explain the significant difference between the SRR of Palmaz-Schatz and Wallstents despite good results by angiography and visual assessment of the ICUS images for both stent types (Fig. 5). In this study, segments treated by Wallstents, which were significantly longer than Palmaz-Schatz stents, showed relatively more pronounced vessel tapering, demon- 
strated by the difference between the ICUS-measured proximal and distal reference lumen area that for the Wallstent was almost threefold greater than for the Palmaz-Schatz stent. Indeed, it is evident that a minimal lumen area at the distal end of a tapering stent may not meet the criterion of an SRR $\geq 0.8$ if the difference between the distal and proximal reference lumen area is great, resulting in a relatively large mean reference lumen area. This is supported by the finding that the difference between proximal and distal reference lumen area of the Wallstents that met the SRR criterion was particularly low. The ICUS adequacy of the Palmaz-Schatz stent group supports previous observations reporting a $40 \%$ incidence of inadequate results after angiographically optimized stent expansion, ${ }^{11}$ but data for the Wallstent have yet to be reported.

2D and 3D ICUS. Similar results for the various parameters were obtained by $2 \mathrm{D}$ and $3 \mathrm{D}$ ICUS. Measurements of the minimal lumen area by 3D ICUS were almost identical to those of 2D ICUS for the Wallstents. For the Palmaz-Schatz stents, a nonsignificant overestimation by the 2D ICUS was observed, but it remains unclear why this slight difference between 2D and 3D measurements was only observed in the relatively shorter Palmaz-Schatz stents and not in Wallstents. An overestimation of the minimal lumen area measurements by 2 D ICUS may be expected because some sites of the vessel segment may be missed by visual examination and conventional 2D assessment. The differences between $2 \mathrm{D}$ and $3 \mathrm{D}$ measurements in this study may be small for two reasons. First, a motorized pullback of the ICUS transducer was performed, ensuring that 2D ICUS images of all sites of the entire vascular segment were equally displayed. This view may not always be guaranteed if the ICUS catheter is manipulated by hand. Second, the experience of the analysts who had previously performed more than 100 3D ICUS examinations enabled them to mentally obtain an approximate spatial picture of the vessel segment by 2 D ICUS information.

Limitations. This study provides an insight into the clinical practice of the optimized expansion of the Palmaz-Schatz stent and Wallstent. The patient population was unselected and included a number of Wallstents in vein grafts. Because vein grafts show less vessel tapering than native coronary arteries and most Wallstents with adequate stent expansion by ICUS were placed in bypass grafts, differences between the ICUS findings of Palmaz-Schatz and Wallstents observed in this study are likely to be even more pronounced in a series of native coronary arteries. Further trials should try to address the is-

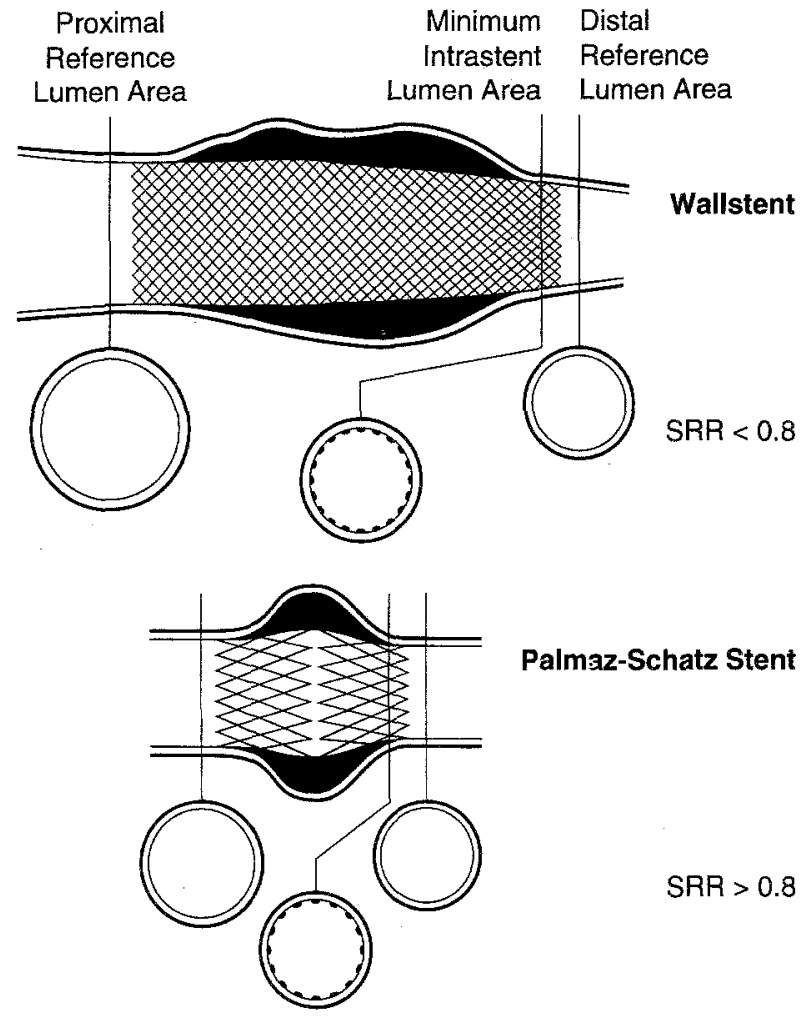

SRR $=\frac{\text { Minimum Intrastent Lumen Area }}{\text { Average of Proximal and Distal Reference Lumen Area }}$

Fig. 5. Possible explanation for difficulty in achieving $\mathrm{SRR} \geq 0.8$ after Wallstent implantation. In this scheme Wallstent clearly tapers and does not fulfill SRR criterion because minimal lumen area is located near distal reference site, with lumen dimensions significantly smaller than proximal reference. Example of Palmaz-Schatz stent, however, shows little vessel tapering and is much more likely to fulfill SRR criterion.

sues raised by this study in homogeneous populations of either native coronary arteries or venous bypass grafts. Coronary angiography displays only the silhouette of the opacified lumen and provides no direct information on the apposition of the stent to the vessel wall. In clinical practice quantitative angiography ${ }^{39}$ is further limited by foreshortening and overlapping vessels. The use of a distal reference diameter to calculate the percent diameter stenosis after stenting introduces certain subjectivity; however, this on-line QCA approach is feasible for the analysis after optimized stent deployment and takes the frequently fusiform angiographic shape of the stented vessel into account.

ICUS consistently yields larger values of the luminal dimensions compared with quantitative angiography ${ }^{50}$ and has some inherent limitations, such as the dependence on the angle of incidence of the 
ultrasound beam and the relatively high variability of measurements on the basis of manual tracing. ${ }^{51}$ The variability of measurements can be minimized by semiautomated boundary detection in $3 \mathrm{D}$ reconstructed ICUS. ${ }^{25,} 29,41,52-54$ In this 3D ICUS study, the automated lumen detection was sometimes impaired by the echo shade behind larger deposits of calcium, and the quality of the $3 \mathrm{D}$ reconstruction was occasionally limited by artifacts resulting from the cyclic movement of the ICUS catheter and systolicdiastolic changes of the lumen dimensions. ${ }^{25,27,29}$ The latter problem will be solved in the future by ECG-gated 3D reconstruction. ${ }^{29}$ Because the 3D reconstructed view does not depict the true spatial orientation of the vessel segment, ${ }^{29}$ careful interpretation by an experienced investigator was required.

Conclusions. Optimized stent expansion by highpressure inflations of oversized balloons provided excellent angiographic results for both PalmazSchatz stents and Wallstents. 2D and 3D ICUS provided on-line valuable additional information without significant differences between the two approaches. The ultrasound criteria for adequate stent expansion, which evolved from the use of ICUS in Palmaz-Schatz stents, indicated a good result in half of the Palmaz-Schatz stents but few Wallstents, although the angiographic findings and visual assessment of the ICUS images suggested a good outcome. Stent symmetry index and apposition to the vessel wall could be well examined in the Wallstents, whereas the stent-reference lumen area ratio (SRR) infrequently fulfilled the ICUS criteria for adequate stent expansion. We suggest that this is likely caused by vessel tapering and differences between the proximal and distal reference lumen dimensions. Thus the standard SRR criterion appears to be unsuitable in assessing relatively long stents such as the Wallstent.

\section{REFERENCES}

1. Colombo A, Goldberg SL, Almagor Y, Maiello L, Finci L. A novel strategy for stent deployment in the treatment of acute or threatened closure complicating balloon coronary angioplasty: use of a short or standard (or both) single or multiple Palmaz-Schatz stents. J Am Coll Cardiol 1993;22:1887-91.

2. De Feyter PJ, De Scheerder I, Van den Brand M, Laarman GJ, Suryapranata H, Serruys PW. Emergency stenting for refractory acute coronary artery occlusion during coronary angioplasty. Am J Cardiol 1993;66:1147-50.

3. Fishman DL, Savage MP, Leon MB, Schatz RA, Ellis SG, Cleman MW, et al. Effect of intracoronary stenting on intimal dissection after balloon angioplasty: results of quantitative coronary analysis. J Am Coll Cardiol 1991;18:1445-51.

4. George BS, Voorhees WD, Roubin GS, Fearnot NE, Pinkerton CA, Raizner $\mathrm{AE}$, et al. Multicenter investigation of coronary stenting to treat accute or threatened closure after percutaneous transluminal coronary angioplasty: clinical and angiographic outcomes. J Am Coll Cardiol 1993;22:135-43.
5. Haude M, Erbel R, Straub U, Dietz U, Schatz R, Meyer J. Results of intracoronary stents for management of coronary dissection after balloon angioplasty. Am.J Cardiol 1991;67:691-6.

6. Herrman HC, Buchbinder M, Clemen MW, Fishman D, Goldberg S, Leon $\mathrm{MB}$, et al. Emergent use of balloon-expandable coronary artery stenting for failed percutaneous transluminal coronary angioplasty. Circulation 1992;86:812-9.

7. Maiello L, Colombo A, Gianrossi R, McCanny R, Finci L. Coronary stenting for treatment of acute or threatened closure following dissection after coronary balloon angioplasty. Am Heart J 1993;125: 1570-5.

8. Roubin GS, Cannon AD, Agrawal SK, Macander PJ, Dean LS, Baxley WA, et al. Intracoronary stenting for acute and threatened closure complicating percutaneous transluminal coronary angioplasty. Circulation 1992;85:916-27.

9. Sigwart U, Puel J, Mirkovitch V, Joffre F, Kappenberger L. Intravascular stents to prevent occlusion and restenosis after transluminal angioplasty. N Engl J Med 1987;316:701-6.

10. van Beusekom HMM, Serruys PW, van der Giessen WJ. Coronary stent coatings. Coron Art Dis 1994;5;590-6.

11. Colombo A, Hall P, Nakamura S, Almagor Y, Maiello L, Martini G, et al. Intracoronary stenting without anticoagulation accomplished with intravascular ultrasound guidance. Circulation 1995;91:1676-88.

12. Goldberg SL, Colombo A, Nakamura S, Almagor Y, Maiello L, Tobis JM. Benefit of intracoronary ultrasound in the deployment of PalmazSchatz stents. J Am Coll Cardiol 1994;24:996-1003.

13. Nakamura S, Colombo A, Gaglione A, Almagor Y, Goldberg SL, Maiello $\mathrm{L}$, et al. Intracoronary ultrasound observations during stent implantation. Circulation 1994;89:2026-34.

14. Fishman DL, Leon MB, Baim DS, Schatz RA, Savage MP, Penn I, et al. for the Stent REStenosisi Study (STRESS) Investigators. A randomized comparison of coronary stent placement and balloon angioplasty in the treatment of coronary artery disease. N Engl J Med 1994;331:496-501.

15. Serruys PW, de Jaegere P, Kiemeneij F, Macaya C, Rutsch W, Hendrickx G, et al. for the Benestent Study Group. A comparison of balloon expandable stent implantation with balloon angioplasty in patients with coronary artery disease. N Engl J Med 1994;331:489-95.

16. Haude M, Erbel R, Issa H, Straub U, Rupprecht HJ, Treese N, et al. Subacute thrombotic complications after intracoronary implantation of Palmaz Schatz stents. Am Heart J 1993;126:15-22.

17. Reimers B, von Birgelen C, van der Giessen WJ, Serruys PW. A word of caution on optimizing stent deployment in calcified lesions: a case of acute coronary rupture with cardiac tamponade. Am Heart J 1996;131:192-4.

18. Strauss BH, Serruys PW, Bertrand ME, Puel J, Meier B, Goy JJ, et al. Quantitative angiographic follow-up of the coronary Wallstent in native vessels and bypass grafts (European experience--March 1986 to March 1990). Am J Cardiol 1992;69:475-81.

19. Keane D, Buis B, Reifart N, Plokker TH, Ernst J, Mast E, et al. Clinical and angiographic outcome following implantation of the less shortening Wallstent in aorto-coronary vein grafts: introduction of a second generation stent in the clinical arena. J Interven Cardiol 1994;7:557-64.

20. Keane D, de Jaegere P, Serruys PW. Structural design, clinical experience, and current indications of the coronary Wallstent. Cardiology Clinics 1994;12:689-97.

21. Serruys PW, Strauss BH, Beatt KJ, Bertrand M, Puel J, Rickards AF, et al. Angiographic follow-up after placement of a self-expanding coronary stent. N Engl J Med 1991;324:13-7.

22. Strauss BH, Serruys PW. The coronary Wallstent. In: Topol EJ, editor. Textbook of Interventional Cardiology, 2nd ed. Philadelphia: WB Saunders, 1994:687-701.

23. Schatz RA, Baim DS, Leon M, Ellis SG, Goldberg S, Hirshfeld JW, et al. Clinical experience with the Palmaz-Schatz coronary stent (initial results of a multicenter study). Circulation 1991;83:148-61.

24. Haude M. Erbel R, Straub U, Dietz U, Meyer J. Short and long term results after intracoronary stenting in human coronary arteries: monocenter experience with the balloon-expandable Palmaz-Schatz stent. Br Heart J 1991;66:337-45.

25. Di Mario C, von Birgelen C, Prati F, Soni B, Li W, Bruining N, et al Three-dimensional reconstruction of two-dimensional intracoronary 
ultrasound: clinical or research tool? Br Heart J 1995;73(2 Suppl):2632.

26. Matar FA, Mintz GS, Douek P, Farb A, Virmani R, Javier SP, et al. Coronary artery lumen volume measurement using three-dimensional intravascular ultrasound: validation of a new technique. Cathet Cardiovasc Diagn 1994;33:214-20.

27. Roelandt JRTC, Di Mario C, Pandian NG, Li W, Keane D, Slager CJ, et al. Three-dimensional reconstruction of intracoronary ultrasound images: rationale, approaches, problems, and directions. Circulation 1994;90:1044-55.

28. Rosenfield K, Losordo DW, Ramaswamy K, Pastore JO, Langevin E, Razvi $S$, et al. Three-dimensional reconstruction of human coronary and peripheral arteries from images recorded during two-dimensional intravascular ultrasound examination. Circulation 1991;84:1938-56.

29. von Birgelen C, Di Mario C, Prati F, Bruining N, Li W, de Feyter PJ, et al. Intracoronary ultrasound: three-dimensional reconstruction techniques. In: de Feyter PJ, Dì Mario C, Serruys PW, editors. Quantitative coronary imaging. Rotterdam: Barjesteh Meeuwes, 1995:18197.

30. Mintz GS, Pichard AD, Satler LF, Popma JJ, Kent KM, Leon MB. Three-dimensional intravascular ultrasonography: reconstmuction of endovascular stents in vitro and in vivo. Clin Ultrasound 1993;21:60915.

31. Schryver TE, Popma JJ, Kent KM, Leon MB, Eldredge S, Mintz GS. Use of intracoronary ultrasound to identify the "true" coronary lumen in chronic coronary dissection treated with intracoronary stenting. Am J Cardiol 1992;69:1107-8.

32. Mudra H, Klauss V, Blasini R, Kroetz M, Rieber J, Regar E, et al. U1trasound guidance of Palmaz-Schatz intracoronary stenting with a combined intravascular ultrasound balloon catheter. Circulation 1994;90:1252-61.

33. Painter JA, Mintz GS, Wong SC, Popma JJ, Pichard AD, Kent KM, et al. Serial intravascular ultrasound studies fail to show evidence of chronic Palmaz-Schatz stent recoil. Am J Cardiol 1995;75:398-400.

34. Kiemeneij F, Laarman GJ, Slagboom T. Mode of deployment of coronary Palmaz-Schatz stents after implantation with the stent delivery system: an intravascular ultrasound study. Am Heart J $1995 ; 123: 638-44$.

35. Laskey WL, Brady ST, Kussmaul WG, Waxler AR, KroI J, Herrmann $\mathrm{HC}$, et al. Intravascular ultrasonographic assessment of the results of coronary artery stenting. Am Heart J 1993;125:1576-83.

36. Prati F, Di Mario C, von Birgelen C, Gil R, de Feyter PJ, de Jaegere P, et al. Usefulness of on-line 3D reconstruction for stent implantation [abstract]. J Am Coll Cardiol 1995;25:9-10A.

37. Ellis SG, Vandormael MG, Cowley MJ, Di Sciascio G, Deligonul U, Topol EJ, et al. and the multivessel angioplasty prognosis group. Coronary morphologic and clinical determinants of procedural outcome with angioplasty for multivessel coronary disease. Circulation 1990;82:1193202.

38. Ryan TJ, Faxon DP, Kennedy JW, King SB III, Loop FD, Peterson KL, et al. Guidelines for percutaneous transluminal coronary angioplasty: a report of the American College of Cardiology/American Heart Association task force on assessment of diagnostic and therapeutic cardiovascular procedures (subcommittee on percutaneous transluminal coronary angioplasty). J Am Coll Cardiol 1988;12:529-45 and Circulation 1988;78:486-502

39. Keane D, Serruys PW. Quantitative coronary angiography: an integral component of interventional cardiology. In: Topol EJ, Serruys PW, ed- itors. Current review of interventional cardiology, 2nd ed. Philadelphia: Current Medicine, 1995:205-33.

40. Haase J, Escaned J, van Swijndregt EM, Ozaki Y, Gronenschild E, Slager CJ, et al. Experimental validation of geometric and densitometric coronary measurements on the new generation cardiovascular angiography analysis system. Cathet Cardiovasc Diagn 1993;30:104-14.

41. Hausmann D, Friedrich G, Sudhir K, Mullen WL, Soni B, Fitzgerald PJ, et al. 3D intravascular ultrasound imaging with automated border detection using 2.9 F Catheters [abstract]. J Am Coll Cardiol 1994;23:174A.

42. De Jaegere PP, Strauss BH, van der Giessen WJ, de Feyter PJ, Serruys PW. Immediate changes in stenosis geometry following stent implantation: comparison between a self-expandable and a balloon expandable stent. J Interven Cardiol 1992;5:71-8

43. Ge J, Erbel R, Gerber T, Gorge G, Koch L, Haude M, et al. Intravascular ultrasound imaging of angiographically normal coronary arteries: a prospective study in vivo. $\mathrm{Br}$ Heart $\mathrm{J} 1994 ; 71: 572-8$.

44. Nissen SE, Gurley JC, Grines CL, Booth DC, McClure R, Berk M, et al. Intravascular ultrasound assessment of lumen size and wall morphology in normal subjects and patients with coronary artery disease. Cireulation 1991;84:1087-99.

45. Tobis JM, Mallery J, Mahon D, Lehmann K, Zalesky P, Griffith J, et al. Intravascular ultrasound imaging of human coronary arteries in vivo. Circulation 1991;83:913-26.

46. Mudra H, Blasini R, Regar E, Klauss V, Rieber J, Theisen K. Intravascular ultrasound assessment of the balloon-expandable Palmaz-Schatz coronary stent. Coron Art Dis 1993;4:791-99.

47. Slepian MJ. Application of intraluminal ultrasound imaging to vascular stenting. Int J Card Imaging 1991;6:285-311.

48. Tenaglia AN, Kisslo K, Kelly S, Hamm MA, Crowely R, Davidson CJ. Ultrasound guide wire-directed stent deployment. Am Heart J 1993;125:1213-6

49. Javier SP, Mintz GS, Popma JJ, Pichard AD, Kent KM, Satler LF, et al. Intravascular ultrasound assessment of the magnitude and mechanism of coronary artery and lumen tapering. Am J Cardiol 1995;75:17780.

50. Haase J, Ozaki Y, Di Mario C, Escaned J, De Feyter PJ, Roelandt JRTC, et al. Can intracoronary ultrasound correctly assess the luminal dimensions of coronary artery lesions? A comparison with quantitative angiography. Eur Heart J 1995;16:112-9.

51. Hausmann D, Lundkvist AJS, Friedrich GJ, Mullen WL, Fitzgerald PJ, Yock PG. Intracoronary ultrasound imaging: intraobserver and interobserver variability of morphometric measurements. Am Heart J 1994;128:674-80.

52. von Birgelen C, Di Mario C, Li W, Camenzind E, Ozaki Y, de Feyter PJ, et al. Volumetric quantification in intracoronary ultrasound: validation of a new automatic contour detection method with integrated user interaction [abstract]. Circulation 1994;90:I-550.

53. von Birgelen C, Di Mario C, Li W, Schuurbiers JCH, Slager Cj, Ruygrok $P$, et al. Clinical application of a new computerized method measuring coronary artery dimensions by three-dimensional intracoronary ultrasound: reproducibility in vivo during coronary interventions [abstract], Eur Heart J 1995;16:428.

54. Sonka M, Zhang X, Siebes M, DeJong S, McKay CR, Collins SM. Automated segmentation of coronary wall and plaque from intravascular ultrasound image sequences. In: Computers in cardiology 1994. Los Alamitos, Calif:: TEEE Computer Society Press, 1994:281-4. 